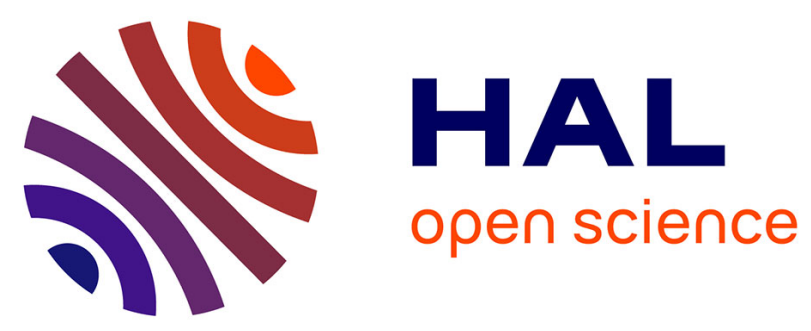

\title{
Near Breakdown Voltage Optical Beam Induced Current (OBIC) on 4H-SiC Bipolar Diode
}

Dominique Planson, Besar Asllani, Hassan Hamad, Marie-Laure Locatelli, R Arvinte, Christophe Raynaud, Pascal Bevilacqua, Luong Viet Phung

\section{To cite this version:}

Dominique Planson, Besar Asllani, Hassan Hamad, Marie-Laure Locatelli, R Arvinte, et al.. Near Breakdown Voltage Optical Beam Induced Current (OBIC) on 4H-SiC Bipolar Diode. Materials Science Forum, 2018, Silicon Carbide and Related Materials 2017, 924, pp.577-580. 10.4028/www.scientific.net/MSF.924.577 . hal-01818806

\section{HAL Id: hal-01818806 https://hal.science/hal-01818806}

Submitted on 19 Jun 2018

HAL is a multi-disciplinary open access archive for the deposit and dissemination of scientific research documents, whether they are published or not. The documents may come from teaching and research institutions in France or abroad, or from public or private research centers.
L'archive ouverte pluridisciplinaire HAL, est destinée au dépôt et à la diffusion de documents scientifiques de niveau recherche, publiés ou non, émanant des établissements d'enseignement et de recherche français ou étrangers, des laboratoires publics ou privés. 
Near Breakdown Voltage Optical Beam Induced Current (OBIC) on 4H-SiC Bipolar Diode

\author{
D. Planson ${ }^{1, a^{*}}$, B. Asllani ${ }^{1, ~ b}$, H. Hamad ${ }^{1, c}$, M.-L. Locatelli ${ }^{2,3, d}$, R. Arvinte ${ }^{2, e}$, \\ C. Raynaud ${ }^{1, f}$, P. Bevilacqua ${ }^{1, g}$ and L.-V. Phung ${ }^{1, h}$ \\ ${ }^{1}$ Université de Lyon, INSA Lyon, CNRS UMR 5005, Ampère, Lyon, France \\ ${ }^{2}$ Université de Toulouse; UPS, INPT; LAPLACE (Laboratoire Plasma et Conversion d'Energie); \\ 118 route de Narbonne, F-31062 Toulouse cedex 9, France \\ ${ }^{3}$ CNRS; LAPLACE; F-31062 Toulouse, France \\ adominique.planson@insa-lyon.fr, bbesar.asllani@insa-lyon.fr, chassan.hamad@insa-lyon.fr, \\ ${ }^{d}$ marie-laure.locatelli@laplace.univ-tlse.fr, ${ }^{e}$ roxana.arvinte@laplace.univ-tlse.fr, \\ fchristophe.raynaud@insa-lyon.fr, 9pascal.bevilacqua@insa-lyon.fr, hluong-viet.phung@insa-lyon.fr
}

Keywords: 4H-SiC, Bipolar diode, high voltage device, OBIC, TCAD simulation, Electroluminescence.

\begin{abstract}
This paper presents OBIC measurements performed at near breakdown voltage on two devices with different JTE doses. Overcurrent has been measured either at the JTE periphery or at the $\mathrm{P}^{+}$border. Such overcurrent is present due to the electric field enhancement near the breakdown voltage. This hypothesis is proved by the electroluminescence. TCAD simulation of two different JTE doses yielded similar results to the OBIC measurements.
\end{abstract}

\title{
Introduction
}

Silicon Carbide $(\mathrm{SiC})$ is an attractive semiconductor material for high power and high temperature applications. In order to reach the expected breakdown voltage, an effective junction termination is required to spread the peripheral electrical field lines. Among different techniques used for periphery protection, a Junction Termination Extension (JTE) is often chosen. The key parameters are the accurate dose of the electrically activated implanted dopants and the control of the semiconductor surface charge passivation. In order to check the implanted dose, we can use SIMS (Secondary Ion Mass Spectrometry), which is a destructive way to measure the concentration profile of the implanted species. Nevertheless, it does not allow to determine the electrically active dopants, neither is it possible to measure the effective charge density related to the passivation layer used. Optical Beam Induced Current (OBIC) technique is a powerful means to analyze the electric field distribution at the edge of the device periphery without damaging it. In this paper, the OBIC technique is applied to high voltage bipolar diodes to analyze the experimental behavior of the periphery protection with respect to the applied reverse voltage.

\section{Experimental Setup}

In this experimental setup, a $349 \mathrm{~nm}$ UV pulsed laser is used to generate electron-hole pairs (EHPs). An optical bench consisting of two semi-reflecting mirrors and a focusing lens is controlled with LabView to move the position (i.e. on $\mathrm{x}, \mathrm{y}$ and $\mathrm{z}$ ) of the focal point. At the focal point the spot diameter is about $\sim 30 \mu \mathrm{m}$ and the beam power density is up to $100 \mathrm{GW} / \mathrm{cm}^{2}$. This energy is high enough to generate electron-hole pairs (EHPs), so that an OBIC current could be measured. The OBIC principle has already been described in [1]. The high voltage test devices are placed in a vacuum chamber. The laser beam passes through the vacuum chamber window to reach the device under test. The surface of the diode is scanned with a step of $10 \mu \mathrm{m}$ at several voltages. 


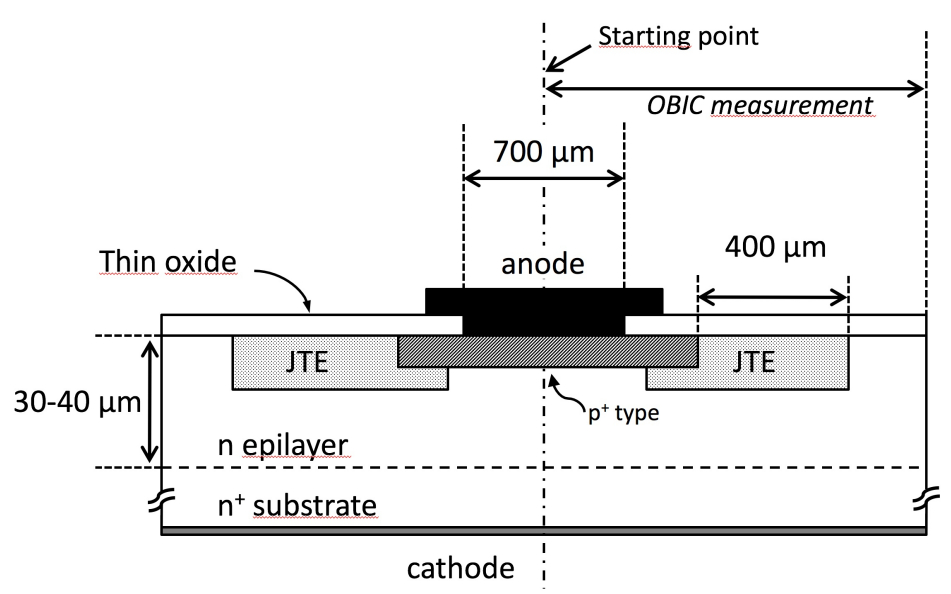

Fig. 1. Cross section of the protected bipolar PiN diode.

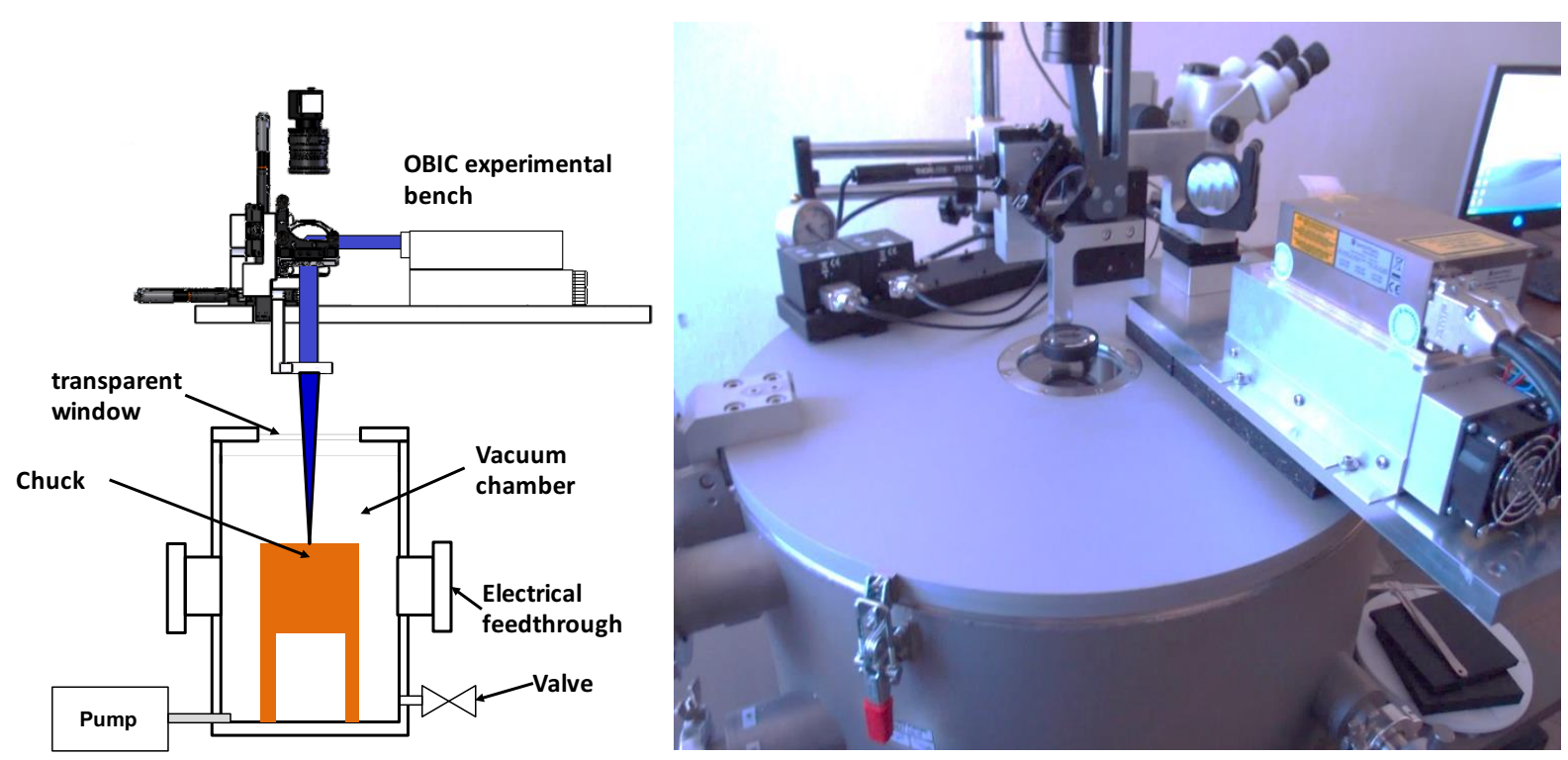

Fig. 2. Schematic of OBIC experimental bench (left), and picture of the setup (right)

The measurements were realized on two different square-shaped bipolar diodes protected with a single JTE, namely device 1 and device 2 . Both devices have been realized on a thick 4H-SiC n-type epilayer, doped at $\sim 1 \times 10^{15} \mathrm{~cm}^{-3}$. The main difference is the Al doping level of the JTE and the epilayer thickness, as described in Table 1.

Table 1. Specifications of the two devices under test

\begin{tabular}{|c|c|c|}
\hline & Device 1 & Device 2 \\
\hline JTE dose $\left[\mathrm{cm}^{-2}\right]$ & $1.23 \times 10^{13}$ & $6.84 \times 10^{12}$ \\
\hline Epilayer thickness $[\mu \mathrm{m}]$ & 40 & 30 \\
\hline
\end{tabular}

The metallized anode contact is square-shaped, with a side length of $720 \mu \mathrm{m}$, and a corner curvature radius of $200 \mu \mathrm{m}$. A cross section of the device is shown in Fig. 1.

The surface of the diode is scanned by the laser beam focused by several lenses to a spot size of $\sim 30 \mu \mathrm{m}$. A schematic description and a picture of the experimental bench are shown in Fig. 2 . The measurement is performed in a vacuum chamber able to sustain high voltages up to $10 \mathrm{kV}$.

\section{Results and Analysis}

Tests have been carried out at voltages between $800 \mathrm{~V}$ to $2850 \mathrm{~V}$ as shown in Fig. 3 for device 1 and for device 2. For the voltages near breakdown the electric field becomes high. Consequently, the 
EHPs, which are generated by the UV beam in the space charge region are accelerated by this high electric field, thereby acquiring enough kinetic energy to generate new EHPs, through impact ionization. This is the pre-avalanche regime, which leads to an increase of the OBIC signal [1].
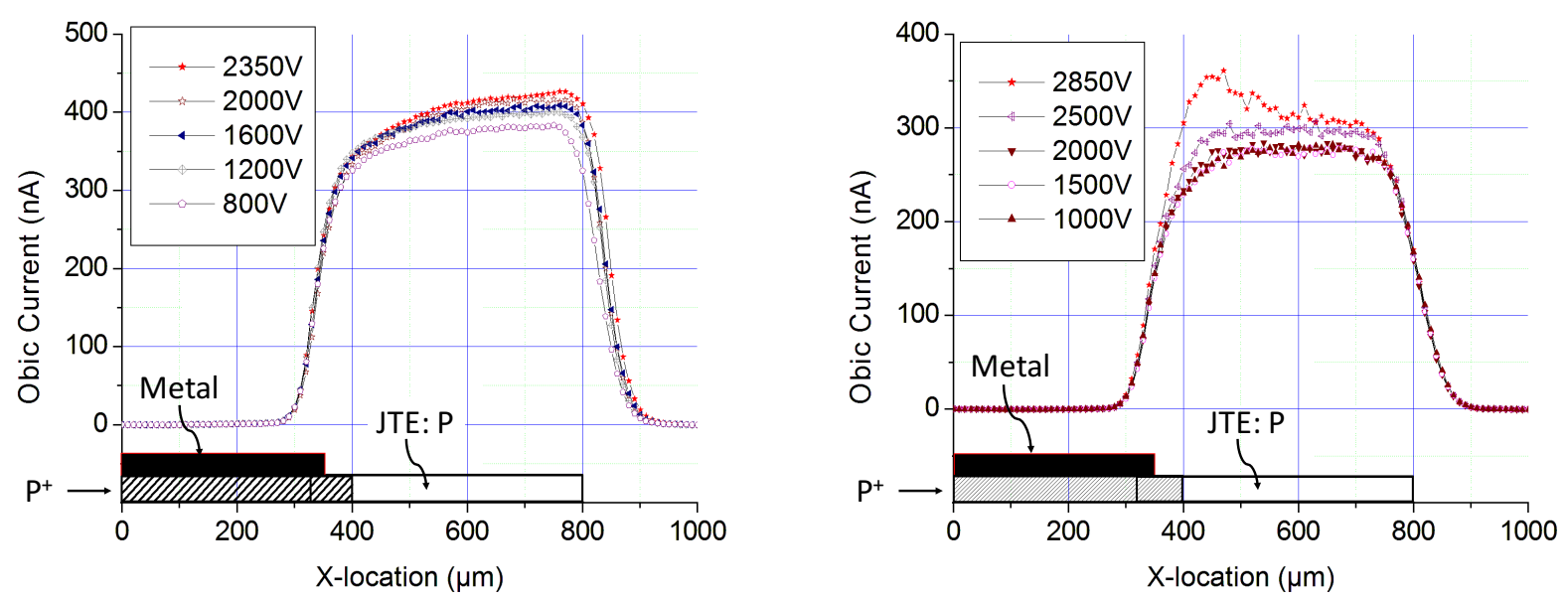

Fig. 3. OBIC current measured at different increasing voltages on device \#1 (left) and device \#2 (right).

For device \#1 having the high JTE dose, an increase in the OBIC signal could be observed at the edge of the JTE near the breakdown voltage. This phenomenon is correlated with the observed electroluminescence due to the radiative recombination of EHPs generated by avalanche multiplication [2-3], as shown in Fig. 4 left.
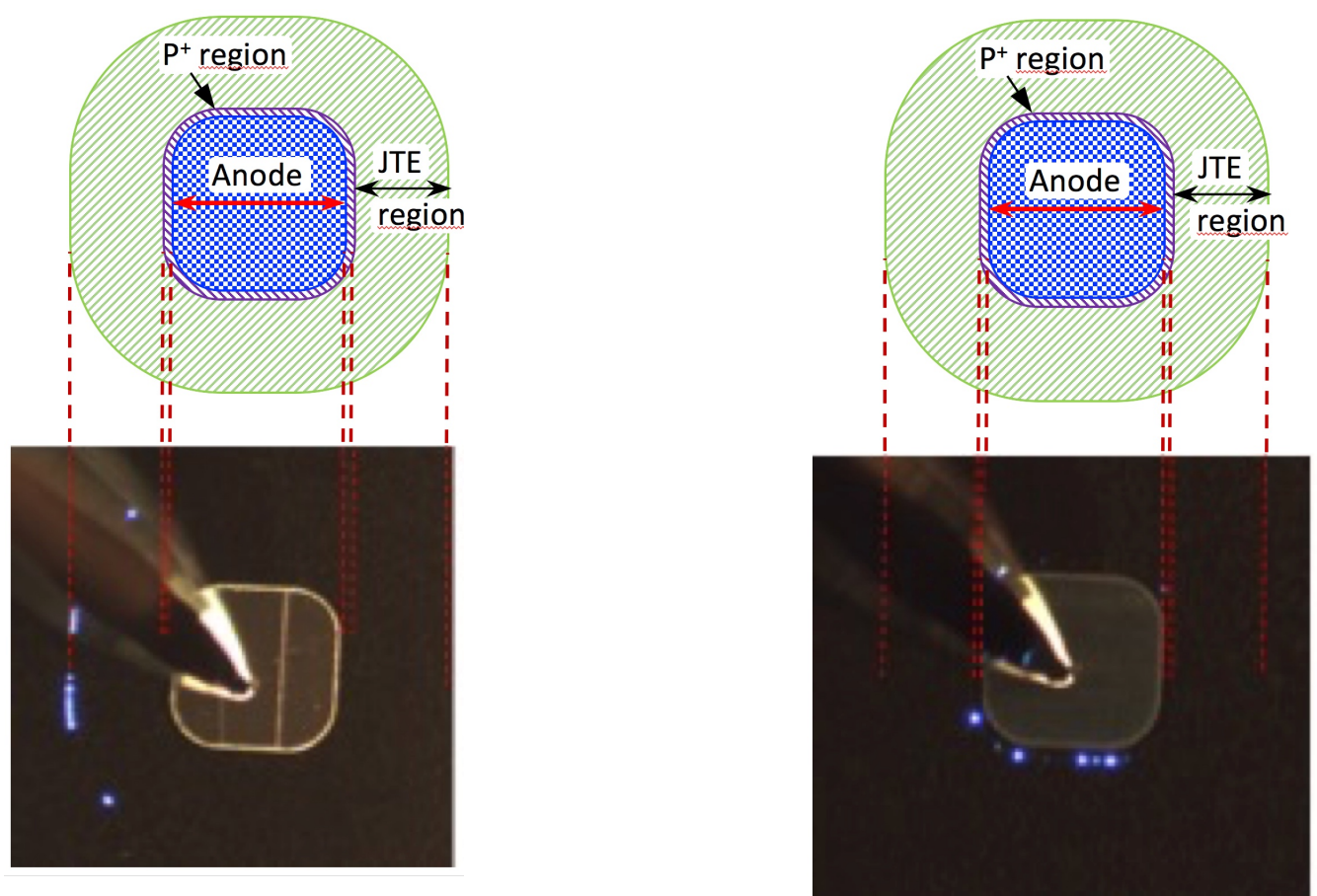

Fig. 4. Electroluminescence observed on device \#1 (left) and device \#2 (right) near breakdown voltage.

For device \#2 having a low JTE dose, near the breakdown voltage an increase in the OBIC signal could be observed at the edge of the $\mathrm{P}^{+}$region. In this case also the phenomenon can be correlated with the observed electroluminescence as shown in Fig. 4 right.

TCAD simulations have been performed on both structures using Sentaurus Synopsys [4]. The description of the device structure takes into account the real doping levels and dimensions. We 
constructed a UV-beam in TCAD that scans the diode's surface and produces an OBIC signal. The simulated induced current and electric field distribution are shown in Fig. 5.
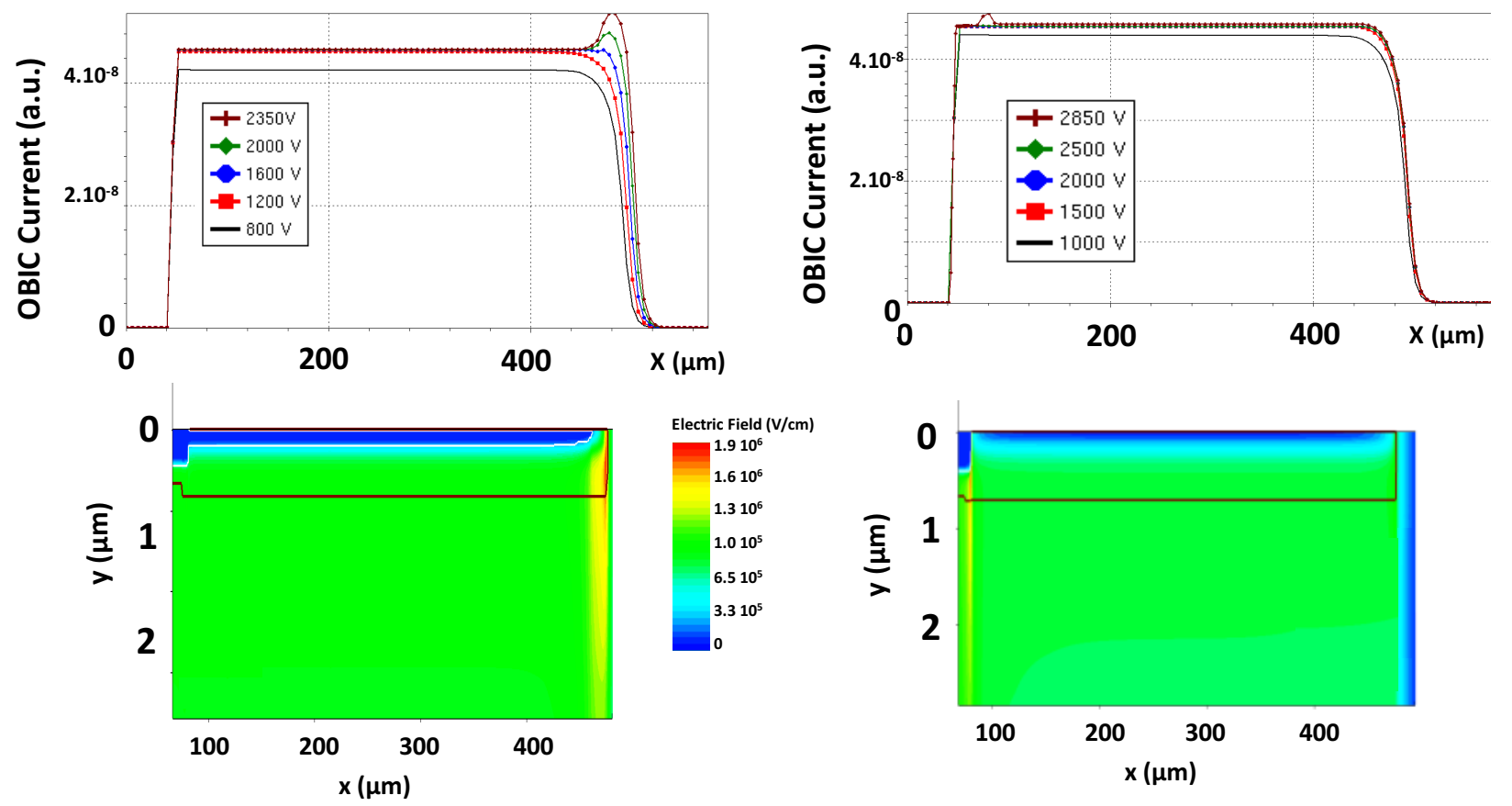

Fig. 5. Simulation results of OBIC current for both structures (device \#1 from $800 \mathrm{~V}$ up to $2350 \mathrm{~V}$ and device \#2 from 1000 up to $2850 \mathrm{~V}$ ) and the corresponding electric field distribution at near breakdown voltage for both cases.

Simulation results confirm that a JTE with a high dose (device \#1) the OBIC signal is more intense at the JTE border, due to higher electric field at this exact point. In the case of the lower JTE dose (device \#2) the highest OBIC current intensity is obtained at the $\mathrm{P}^{+}$border, since the JTE fails to protect and the highest electric field is located at the anode border.

\section{Summary}

This paper presents OBIC measurements performed on JTE-protected bipolar diodes at near breakdown voltages. Two bipolar diodes with different JTE doses (i.e. high and low) have been analyzed. A strong discrepancy appears from one device to another, which is correlated with electroluminescence and simulation results.

\section{Acknowledgments}

The authors would like to thank the FilSiC research program for financial support and also gratefully acknowledge Dr. Gregory GROSSET and Lionel DUPUY for the realization of test structures.

\section{References}

[1] H. Hamad, C. Raynaud, P. Bevilacqua, S. Scharnholz, D. Planson, Materials Science Forum Vols. 821-823 (2015), p. 223-228.

[2] S. Ono, M. Arai, C. Kimura, Japanese Journal of Applied Physics Vol. 43, nº 10 (2004), p. $7107-$ 7108 .

[3] K. Mochizuki, H. Okino, H. Matsushima, Y. Toyota, Materials Science Forum Vols. 821-823 (2015), p. 640-643.

[4] Sentaurus Device User Guide Version F-2017, http://www.synopsys.com/home.aspx 